\title{
Toxicity of Rubratoxin B to Fungi
}

\author{
By J. REISS \\ Mikrobiologisches Laboratorium der Grahamhaus Studt K.G., \\ 655 Bad Kreuznach, Germany
}

(Accepted for publication I9 January 1972)

\begin{abstract}
SUMMARY
The fungi Aspergillus flavus, A. niger, Penicillium expansum, Neurospora crassa, Cladosporium herbarum, Mucor spinosus and Rhizopus nigricans were cultivated (i) in malt extract solutions with various concentrations of rubratoxin B (100, 10, I $\mu \mathrm{g} / \mathrm{ml}$ ) in order to study the hyphal morphology and (ii) on filter discs containing different amounts of the same toxin (IOO, IO, I $\mu \mathrm{g} /$ disc) to detect any influence on sporulation. In the presence of $100 \mu \mathrm{g}$ toxin $/ \mathrm{ml}$ the hyphal tips of $A$. niger and $A$. flavus were very often swollen and much septate, or were transformed into giant cells. Plasmoptysis often occurred. The germ tubes of $R$. nigricans were much deformed. It is assumed that all these toxic effects were caused by weakening of the hyphal tips by interference with wall synthesis. Rubratoxin B ( $100 \mu \mathrm{g} / \mathrm{disc}$ ) completely inhibited the sporulation of all of the fungi. Lower concentrations diminished sporulation of most of the fungi.
\end{abstract}

\section{INTRODUCTION}

The rubratoxins A and B were isolated by Townsend, Moss \& Peck (I966) from cultures of Penicillium rubrum. The chemical structure of the two compounds was elucidated by Moss, Robinson \& Wood (1967, I968), Moss, Robinson, Wood, Paisley \& Feeney (1968) and Moss, Wood \& Robinson (I969) and conditions for biosynthesis of rubratoxin B were reported by Hayes \& Wilson (I968). Both substances are potent hepatotoxins to mice and rats (Townsend et al. 1966; Edwards \& Wogan, 1968). According to Natori et al. (1970) $P$. purpurogenum can also produce rubratoxin $\mathrm{B}$.

Very little is known about the toxicity of rubratoxin B to fungi. Using the agar streak method with filter discs, Hayes \& Wyatt (1970) could not observe any effect of this compound on the development of some fungi. As it is known that the mycotoxin aflatoxin $\mathbf{B}_{1}$ can affect fungi in many different ways (Lillehoj, Ciegler \& Hall, I967; Ong, 1970; Reiss, I $970 a$, I97I $a, b$ ), a study was undertaken to establish whether rubratoxin B also can be harmful to fungi. This paper presents information on the influence of rubratoxin $B$ on morphology and sporulation of some fungi.

\section{METHODS}

The following fungi were used: Aspergillus flavus (IMI 897I7; Commonwealth Mycological Institute, Kew, Surrey), A. niger (strain D3 from the collection of the Institute of Special Botany, University of Mainz, Germany), Penicillium expansum (strain DI9), Neurospora crassa (strain DI2), Cladosporium herbarum (strain F4), Mucor spinosus (strain B5) and Rhizopus nigricans (strain B20). Stock cultures were prepared in Petri dishes on malt extract agar $(4 \%, \mathrm{w} / \mathrm{v}$, malt extract; $0.5 \%$ peptone; $2.5 \%$ agar $)$. 
To detect any influence of the toxin on the morphology of hyphae, the fungi were cultured for $24 \mathrm{~h}$ on cover glasses in malt extract solution $(\mathrm{I} \cdot 7 \% \mathrm{w} / \mathrm{v}$, malt extract; $0.3 \%$ peptone). Solutions with different amounts $(200,20,2 \mu \mathrm{g} / \mathrm{ml})$ of rubratoxin B (Makor Chemicals Ltd, Jerusalem, Israel) in $0.3 \%$ dimethylformamide (DMF) $(2 \mathrm{ml})$ were added to doublestrength malt extract solution $(2 \mathrm{ml}$.) so that the final toxin concentrations were 100 , I0 and I $\mu \mathrm{g} / \mathrm{ml}$. To avoid its destruction the toxin solutions in $0.3 \%$ DMF were not sterilized, but all other solutions, the cover glasses and the moist chambers were sterile. Bacterial growth never occurred. Controls were prepared in a similar way except that either $0.3 \% \mathrm{DMF}$ without toxin or distilled water was used instead of rubratoxin B solutions. In all test solutions the final concentration of the solvent DMF was $0.15 \%(\mathrm{v} / \mathrm{v})$ and the final $\mathrm{pH}$ was $5 \cdot 6$. The cover glass preparations were inoculated with spores removed from stock cultures by means of a sterile needle and cultivated in moist chambers at 20 to $22{ }^{\circ} \mathrm{C}$ in darkness to avoid any destruction of the toxin. For microscopic observation the cover glasses were turned over and laid on slides.

Sporulation of the fungi was studied with filter discs containing rubratoxin B as has been described elsewhere for aflatoxin tests (Reiss, 197 $a$ ). The toxin was dissolved in acetone and filter discs with 100 , Io and I $\mu$ g toxin were prepared. The controls were filters soaked with acetone and subsequently dried (control a) or discs without any pretreatment (control b). The filter discs containing toxin, malt extract solution and spores as well as the controls were incubated in micro-cultivation chambers (Reiss, I970 $b$ ) in darkness at 20 to $22{ }^{\circ} \mathrm{C}$.

\section{RESULTS}

\section{Influence of rubratoxin $B$ on morphology of hyphae}

After an incubation period of $24 \mathrm{~h}$ many abnormalities could be observed in Aspergillus niger, A. flavus and Rhizopus nigricans, whereas the other test fungi had grown normally. Aspergillus niger hyphae showed the greatest damage. Very often the tips were ruptured and the contents extruded (Fig. I). Usually the hyphae survived the damage and continued to grow with reduced diameter (Fig. 2). Frequently the ends of short hyphal branches were swollen and much septate or had formed spherical bodies with diameters of 18 to $2 \mathrm{I} \mu \mathrm{m}$ (Fig. 3, 4). Such malformations occurred especially often after culture in malt extract solution with $100 \mu \mathrm{g}$ toxin/ml for $24 \mathrm{~h}$ and could also be observed in preparations with Io $\mu \mathrm{g}$ toxin $/ \mathrm{ml}$ after $48 \mathrm{~h}$. In both controls the hyphae were normal (Fig. 5).

The morphology of the hyphae of Aspergillus favus was affected by rubratoxin $\mathbf{B}$ after $24 \mathrm{~h}$. After culture in nutrient with $100 \mu \mathrm{g}$ and Io $\mu \mathrm{g}$ toxin $/ \mathrm{ml}$ many hyphal branches

Fig. I. Plasmoptysis in Aspergillus niger after one day in malt extract solution with $100 \mu \mathrm{g}$ rubratoxin $\mathrm{B} / \mathrm{ml}$.

Fig. 2. Plasmoptysis and newly formed hypha in Aspergillus niger after one day in malt extract solution with $\mathrm{I} 00 \mu \mathrm{g}$ rubratoxin $\mathrm{B} / \mathrm{ml}$.

Fig. 3 and 4: Spherical bodies in Aspergillus niger after one day in malt extract solution with $100 \mu \mathrm{g}$ rubratoxin $\mathrm{B} / \mathrm{ml}$.

Fig. 5. Normal hyphae of Aspergillus niger after one day in malt extract solution (control).

Fig. 6. Swollen and septate hypha of Aspergillus flavus after one day in malt extract solution with I $00 \mu \mathrm{g}$ rubratoxin $\mathrm{B} / \mathrm{ml}$.

Fig. 7. Abnormal germ tubes of Rhizopus nigricans after one day in malt extract solution with $100 \mu \mathrm{g}$ rubratoxin $\mathrm{B} / \mathrm{ml}$. 

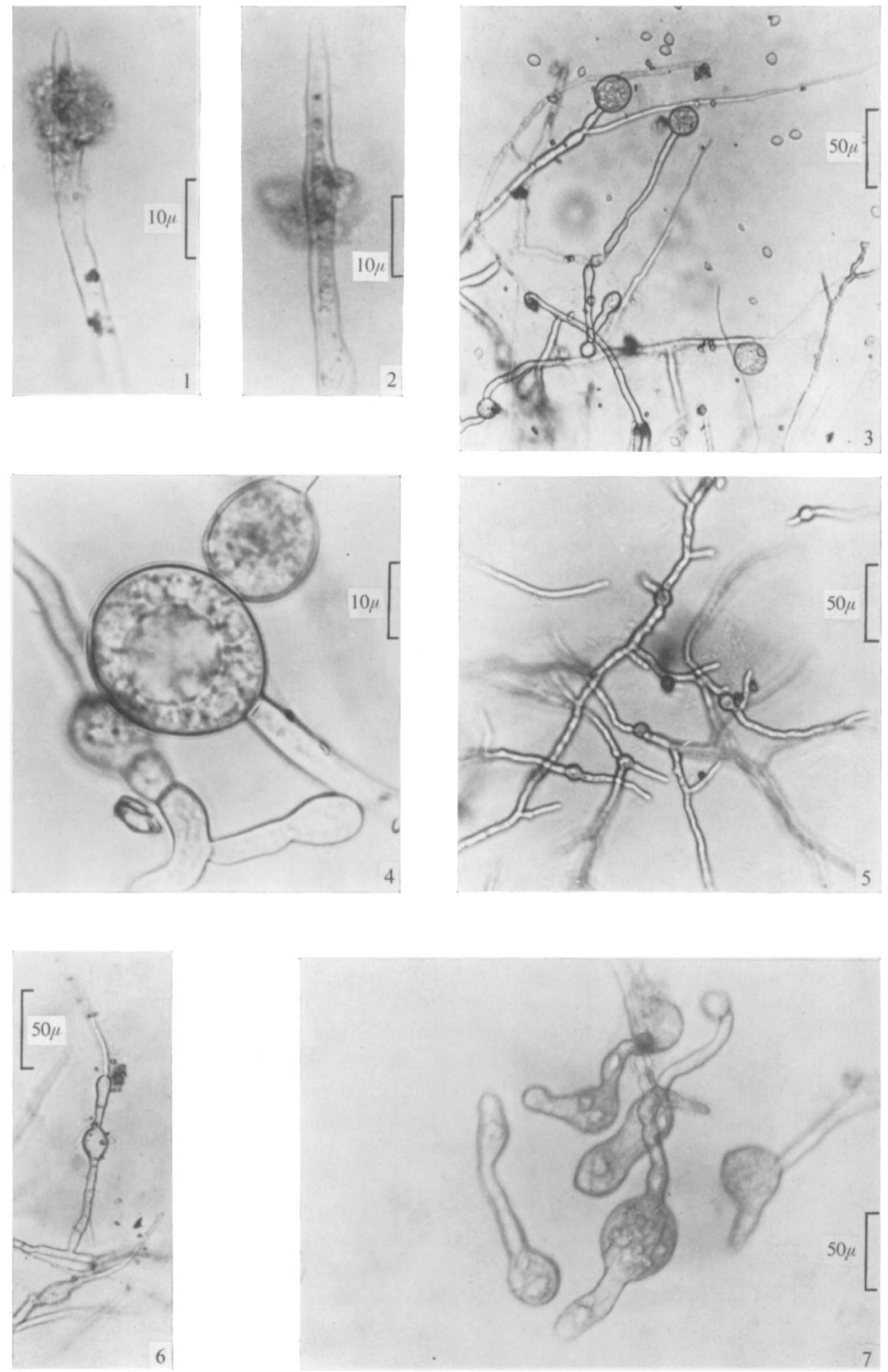


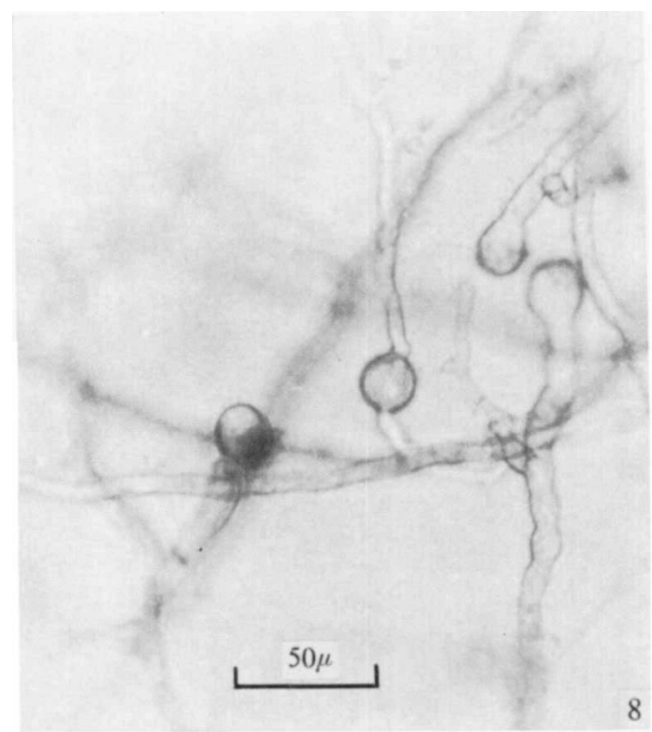

Fig. 8. Normal germ tubes of Rhizopus nigricans after one day in malt extract solution (control).

Table I. Intensity of sporulation of fungi after 3 days under the influence of different concentrations of rubratoxin $B$ (expressed in $\mu \mathrm{g} /$ disc)

\begin{tabular}{|c|c|c|c|c|c|}
\hline & & Rubrato & & & \\
\hline & 100 & 10 & $\mathbf{I}$ & control a & control b \\
\hline Aspergillus flavus & - & + & + & +++ & $++t$ \\
\hline A. niger & - & +++ & +++ & +++ & +++ \\
\hline Penicillium expansum & - & +++ & +++ & +++ & +++ \\
\hline Neurospora crassa & - & ++ & +++ & +++ & +++ \\
\hline Cladosporium herbarum & - & $++t$ & $++t$ & +++ & $++t$ \\
\hline Mucor spinosus & - & - & + & ++ & ++ \\
\hline Rhizopus nigricans & - & - & ++ & ++ & ++ \\
\hline
\end{tabular}

+++ , Heavy sporulation; ++ , moderate sporulation; + , mature or developing sporangia rare; - , no sporulation.

were swollen and much septate (Fig. 6), as with A. niger. Other damage was not observed. In both controls the hyphae had developed normally.

The malformations of the hyphae of Rhizopus nigricans were of a different kind. After culture for $24 \mathrm{~h}$ in malt extract solution with $100 \mu \mathrm{g}$ toxin/ml all spores had germinated; however, all the germ tubes were short and of irregular shape. Their diameter was much greater than that of normal hyphae (Fig. 7,8 ). In solutions with $10 \mu \mathrm{g}$ and I $\mu \mathrm{g}$ toxin/ml as well as in both controls normal mycelium had developed (Fig. 8).

\section{Influence of rubratoxin $B$ on sporulation}

Rubratoxin $B$ in high concentration inhibited the sporulation of all the fungi tested as is shown in Table $\mathrm{r}$.

After cultivation in the presence of $10 \mu \mathrm{g}$ toxin/disc the conidial heads of Aspergillus niger were simpler and the conidiophores of Neurospora crassa were less branched than they were in the controls. 


\section{DISCUSSION}

Rubratoxin B damaged the hyphae of Aspergillus niger, A. flavus and Rhizopus nigricans in several different ways. Of special interest was the bursting of the hyphal tips of $A$. niger and the subsequent extrusion of the cytoplasm. Such plasmoptysis phenomena have been observed in different fungi under the influence of hypotonic solutions, e.g. in A. niger (Talburt \& Johnson, 1955), in Neurospora crassa (Robertson \& Rizvi, 1968) and in Trichothecium roseum (Dargent, 1969). Rizvi \& Robertson (1965) reported that the hyphae of $N$. crassa, whose tips had burst as a result of the addition of L-sorbose to the culture medium, after recovery began to grow again with reduced diameter. A similar observation was made with $A$. niger under the influence of rubratoxin B (Fig. 2). According to Rizvi \& Robertson (I965) sorbose weakens the hyphal apex thus causing plasmoptysis. It is possible that rubratoxin B interferes with wall synthesis thus weakening the hyphal tips and leading to plasmoptysis.

'Giant cells' in Aspergillus flavus influenced by aflatoxin have been described by Wildman (I966). It must be assumed that these swellings are the results of a high osmotic pressure of the cytoplasm within a weakened and consequently flexible wall.

The damage to the germ tubes of Rhizopus nigricans is similar to that produced in Thamnidium elegans by aflatoxin $\mathrm{B}_{1}$ (Reiss, $197 \mathrm{I} b$ ) and in Fusarium roseum by toxic fractions of culture filtrates of Phialophora cinerescens (Moreau \& Moreau, 1968). These alterations also could be due to interference by rubratoxin $B$ with wall synthesis at the hyphal tips.

Rubratoxin B (100 $\mu \mathrm{g} /$ disc) completely inhibited sporulation of all the fungi tested and Io $\mu \mathrm{g} /$ disc that of Aspergillus flavus, Mucor spinosus and Rhizopus nigricans. When comparing the influence of rubratoxin B and aflatoxin $B_{1}$ (Reiss, I97I $a$ ) on different fungi it is evident that the former is the more toxic. Rubratoxin $B$ is also a more potent inhibitor of the germination of seeds of Lepidium sativum than is aflatoxin $\mathrm{B}_{1}$ (Reiss, $197 \mathrm{r} \mid c$ ).

I thank Professor Dr B. Haccius (Institute of Special Botany, University of Mainz) for the fungus cultures and Mr E. Whittacker, B.A., for his help in preparing the manuscript.

\section{REFERENCES}

Dargent, R. (1969). Nouvelles observations sur le phénomène de plasmoptysie. Comptes rendus de l'Académie des sciences, Serie $D$ 269, 882-885.

EDWARDS, G. S. \& Wogan, G. N. (I968). Acute and chronic toxicity of rubratoxin in rats. Federation Proceedings 27, 552 .

Hayes, A. W. \& Wilson, B. J. (1968). Bioproduction and purification of rubratoxin B. Applied Microbiology I6, I I63-I 167 .

HAYES, A. W. \& WyATt, E. P. (1970). Survey of the sensitivity of microorganisms to rubratoxin B. Applied Microbiology 20, $164-\mathrm{I} 65$.

LillehoJ, E. B., Ciegler, A. \& Hall, H. H. (I967). Fungistatic action of aflatoxin B. Experientia $23,187$.

Moreau, C. \& Moreau, M. (1968). Recherche des métabolites toxiques du Phialophora cinerescens (Wr.) v. Beyma: altérations des tubes germinatifs chez le Fusarium roseum (Lk.) Sn. et H. (culmorum). Bulletin de la Societé botanique de France II5, 42-47.

Moss, M. O., Robinson, F. V. \& Wood, A. B. (1967). Observations on the structure of the toxins from Penicillium rubrum. Chemistry and Industry $1967,755-757$.

Moss, M. O., Robinson, F. V. \& Wood, A. B. (I968). Rubratoxin B, a toxic metabolite of Penicillium rubrum. Chemistry and Industry 1968, 587-588.

Moss, M. O., Robinson, F. V., Wood, A. B., Paisley, H. M. \& Feeney, J. (I968). Rubratoxin B, a proposed structure for a bis-anhydride from Penicillium rubrum Stoll. Nature, London 220, 767-770. 
Moss, M. O., Wood, A. B. \& Robinson, F. V. (1969). The structure of rubratoxin A, a toxic metabolite of Penicillium rubrum. Tetrahedron Letters, no. 5, 367-370.

Natori, S., Sasaki, S., Kurata, H., Udagawa, S., Ichinoe, M., Saito, M., Umeda, M. \& Ohtsubo, K. (1970). Production of rubratoxin B by Penicillium purpurogenum Stoll. Applied Microbiology 19, 61 3-61 7 .

ONG, T. (1970). Mutagenicity of aflatoxins in Neurospora crassa. Mutation Research 9, 61 5-618.

ReIss, J. (1970 $a$ ). Untersuchungen über den Einfluss von Aflatoxin $\mathbf{B}_{1}$ auf die Morphologie und die cytochemisch fassbare Aktivität einiger Enzyme von Mucor hiemalis (Mucorales). Mycopathologia et mycologia applicata 42, 225-23I.

Reiss, J. (1970b). A simple cultivation chamber for the study of aerial reproductive elements of fungi. Journal of General and Applied Microbiology 16, 185-187.

REISS, J. (1971 a). Inhibition of fungal sporulation by aflatoxin. Archiv für Mikrobiologie 76, 219-222.

ReIss, J. (I97I $b$ ). Hyphenanomalien bei Thamnidium elegans Link durch Aflatoxin $\mathrm{B}_{\mathbf{1}}$. Zeitschrift fiur allgemeine Mikrobiologie Ir, 637-638.

Rerss, J. (197I c). Hemmung der Keimung der Kresse (Lepidium sativum) durch Aflatoxin $\mathbf{B}_{1}$ und Rubratoxin B. Biochemie und Physiologie der Pflanzen I62, 363-367.

Rizvi, S. R. H. \& Robertson, N. F. (1965). Apical disintegration of hyphae of Neurospora crassa as a response to L-sorbose. Transactions of the British Mycological Society 48, 469-477.

Robertson, N. F. \& Rizvi, S. R. H. (1968). Some observations on the water-relations of the hypnat of Neurospora crassa. Annals of Botany 32, 279-29I.

TAlburt, D. E. \& Johnson, G. T. (1955). Plasmoptysis of filamentous fungi. Mycologia 57, 660-662.

Townsend, R. J., Moss, M. O. \& PECK, H. M. (1966). Isolation and characterization of hepatotoxins from Penicillium rubrum. Journal of Pharmacy and Pharmacology 18, 471-473.

Wildman, J. D. (1966). Note on occurrence of giant cells in Aspergillus flavus Link. Journal of the Association of Official Analytical Chemists 49, 562-566. 